Article

\title{
Energy-Saving Network Ventilation Technology of Extra-Long Tunnel in Climate Separation Zone
}

\author{
Chun Guo ${ }^{1, *}$, Jianfeng Xu ${ }^{1}$, Lu Yang ${ }^{2}$, Xiong Guo ${ }^{1}$, Yunlong Zhang ${ }^{1}$ and Mingnian Wang ${ }^{1}$ \\ 1 Key Laboratory of Transportation Tunnel Engineering, Ministry of Education, \\ Southwest Jiaotong University, 111 Erhuan Rd, Chengdu 610031, China; xujf92@163.com (J.X.); \\ guo@my.swjtu.edu.cn (X.G.); yunlongzhang210034@163.com (Y.Z.); mingnianw@163.com (M.W.) \\ 2 College of Foreign Languages, Southwest Jiaotong University, 111 Erhuan Rd, Chengdu 610031, China; \\ yanglu@swjtu.edu.cn \\ * Correspondence: guochun@swjtu.edu.cn; Tel.: +86-138-8218-3775; Fax: +86-28-8760-0612
}

Academic Editors: Eric Ka-wai Cheng and Luisa F. Cabeza

Received: 21 January 2017; Accepted: 23 April 2017; Published: 28 April 2017

\begin{abstract}
Saving energy is a major challenge for the development and safety of the world. Researchers at home and abroad have been continuously working on energy saving technology in the tunnel ventilation for decades. Based on segmented longitudinal ventilation for extra-long road tunnels, the main ventilation mode and utilization method of natural wind energy in extra-long road tunnel were analyzed in this paper. In addition, the possible velocity distribution of natural wind in each section under wind pressure was investigated. Principles of natural wind in each tunnel section were studied based on long-term monitored meteorological factors. Accordingly, a fan equipment configuration method with high guaranteed rate during tunnel operation was proposed. A calculation method for energy-saving network ventilation in the tunnels was established. A feasible and efficient optimized energy-saving ventilation strategy was proposed, which utilizes natural wind and reduces the operation energy consumption. Thus, the annual energy saving in ventilation can reach up to $43.2 \%$ compared to previous energy costs when the intelligent ventilation system works. The research results can properly combine natural wind energy with mechanical ventilation to realize the smart self-energy saving in extra-long tunnels.
\end{abstract}

Keywords: extra-long tunnel; natural wind; energy-saving; control strategy

\section{Introduction}

Climate separation zone usually means the transition region between two different climate zones. Miles of towering mountains stand and interdict the extending of one climate from one side of the mountain to the other side. Rich wind resources in these regions are available for further exploitation but never fully used. Moreover, natural wind, inside the extra-long tunnels located in climatic separation zone, shows more obvious effect on ventilation than in other regions [1,2] and its velocity in the tunnels can be $4-7 \mathrm{~m} / \mathrm{s}$ [3]. However, in the design phase, natural wind is assumed as resistance in the tunnel ventilation modes [4]. Actually, the defect of the assumption is that natural wind sometimes can be assistance. If the traditional ventilation method is applied in the design of extra-long tunnel, the number of fans will be unreasonable. Consequently, traditional ventilation design is not suitable for tunnels in climatic separation zone. In these extra-long tunnels, the control strategy combining natural ventilation and mechanical ventilation together is of great significance.

According to our literature search, different from the abundant research of natural ventilation in building, the application of natural ventilation in long tunnels is rarely reported. Yoon et al. reported that the airflow caused by the natural ventilation pressure is large enough (up to $29.26 \%$ of mechanical ventilation) to increase the efficiency of the ventilation system in tunnels with shaft [5]. Yan et al. 
analyzed the naturally ventilated urban vehicular tunnels with multiple roof openings and held the view that piston effect exists in such tunnels but is weak [6]. Under traffic jam, thermal pressure is a main factor which influences inside flow field [7]. Liu et al. simulated the piston effects in a subway system. He found that a larger sectional area will result in smaller air velocity in shaft and less effective air exchange between tunnel and outside ambient [8].

Mechanical ventilation usually takes up huge space in tunnel for ventilation equipment and costs much for maintenance and electrical energy consumption in operation [9]. In semi-transverse ventilation, the driving space is treated as an air delivery duct or air exhaust duct. If setting air delivery ducts and air exhaust ducts in full-transverse ventilation, no longitudinal wind flow happens inside the tunnel. Good ventilation results are obtained in extra-long tunnels after applying this ventilation mode, but the drawback is high construction costs due to large occupied space in the tunnel [10]. Shafts or inclined shafts serve as air inlets or outlets in segmented longitudinal ventilation, the extra-long tunnel is divided into several segments [11]. Construction expense will obviously decline compared to semi-transverse ventilation [12].

How can sufficient airflow in tunnels be provided with minimum energy consumption? With the development of sensor technology, control strategies of intelligent ventilation were put forward $[13,14]$. Tunnel ventilation is optimized by controlling jet fans and dust collectors installed inside the tunnel [15]. Jet fans blow polluted air outside the tunnel and sensors measure the contents of pollutants in the tunnel. By means of the approach, it was possible to reduce energy consumption while keeping the degree of pollution within allowable range. Modern control methods in tunnel ventilation include fuzzy control, neural networks, expert systems, etc. Several studies about the intelligent control on tunnel ventilation were reported [16-24]. The development tendency of tunnel ventilation will be comprehensive, systematic, intelligent and energy-saving [25].

The Nibashan tunnel is located in climatic separation zone of China. The law of natural wind velocity in the tunnel was studied in this paper. According to the meteorological parameters on both sides of the tunnel and the meteorological principles, the natural wind velocity inside the tunnel was calculated. Then, the idea of different ventilation modes employed in different periods was proposed. Based on the perennial monitoring, the change rules of natural wind in the tunnel were obtained. By adjusting the number of the working fans, the intelligent ventilation will obviously reduce construction investment and operation consumption.

\section{Materials and Methods}

\subsection{Calculation Methods of the Natural Wind Velocity in the Tunnel}

Natural wind pressure of an extra-long highway tunnel is influenced by several factors. These factors include temperature, atmospheric pressure, wind velocity and direction at both ends of the tunnel [26]. The differential pressures are affected by ultra-static pressure difference, thermal-potential pressure difference and ventilation-wall pressure difference. Yoon et al. believed that the longer a ventilation shaft is, the better natural ventilation will be [5]. Natural wind velocity inside a tunnel is influenced by meteorological conditions at the tunnel portals as well as the boundary conditions inside the tunnel [27].

\subsubsection{Calculation Method of the Natural Wind Velocity in the Tunnel without Inclined Shafts}

For tunnels without inclined shafts (Figure 1), the natural wind velocity inside can be calculated as follows $[28,29]$. The calculation method of natural wind resistance for the tunnels without shafts is shown in Equation (1).

$$
\Delta P=\left(\xi_{e n}+\xi_{e x}+\lambda_{r} \cdot \frac{L}{D_{r}}\right) \cdot \frac{\rho_{i}}{2} \cdot v_{i}^{2}
$$




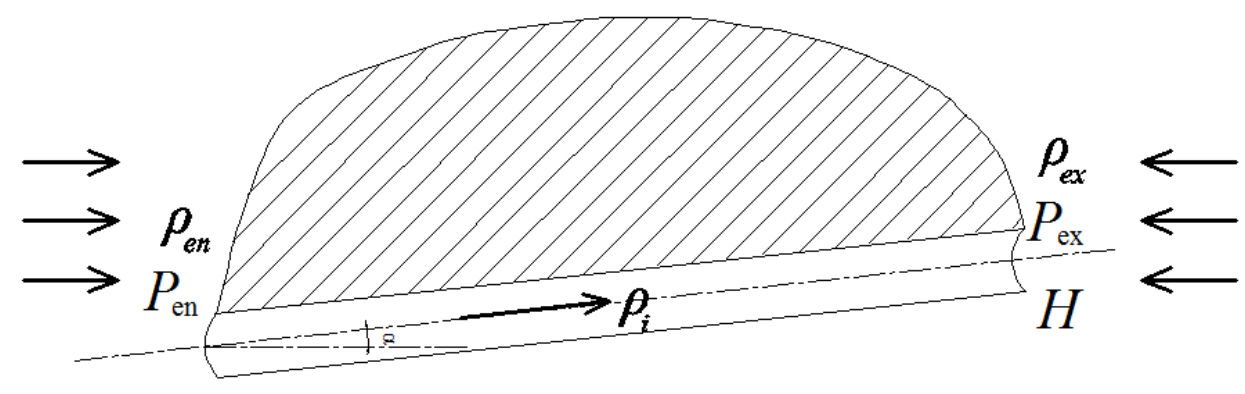

Figure 1. Calculation method of natural wind in the tunnel without shafts.

With the factors influencing the natural wind velocity in the tunnels, $\Delta P$ is composed of ultra-static pressure difference $\left(\Delta P_{u}\right)$, ventilation-wall pressure difference $\left(\Delta P_{w}\right)$ and thermal-potential pressure difference $\left(\Delta P_{t}\right)$, as shown in Equation (2).

$$
\Delta P=\Delta P_{u}+\Delta P_{w}+\Delta P_{t}
$$

During the design phase, the natural wind velocity is often set as $2 \mathrm{~m} / \mathrm{s}-3 \mathrm{~m} / \mathrm{s}$. Based on Equations (1) and (2), Guo et al. proposed a new calculation method for the natural wind velocity inside the tunnel, which is briefly introduced below [30].

If there is no airflow in a tunnel, the static pressure difference between the tunnel portals is equal to the air pressure inside the tunnel produced by gravity. Otherwise, the equation will be false. The differential pressure is called ultra-static pressure difference. The ultra-static pressure difference is calculated as:

$$
\Delta P_{u}=P_{e n}-P_{e x}-\rho_{i} \cdot g \cdot H
$$

The ventilation-wall pressure difference refers to the difference between dynamic pressure and static pressure. After blowing to the tunnel entrance, the natural wind outside the tunnel is decelerated by mountains and then part of the dynamic pressure is converted into static pressure, which is called "ventilation-wall pressure difference". It is calculated as follows [30]:

$$
\Delta P_{w}=0.35 \times \rho_{e n} \cdot\left(v_{\alpha e n} \cdot \cos \alpha_{e n}\right)^{2}-0.35 \times \rho_{e x} \cdot\left(v_{\alpha e x} \cdot \cos \alpha_{e x}\right)^{2}
$$

The difference in the air temperature between inside and outside the tunnel results in different air density. The temperature difference and the elevation difference between two portals of the tunnel will cause pressure difference with airflow, which is called thermo-potential difference [31]. It can be calculated as Equation (5):

$$
\Delta P_{t}=\left(\rho_{\text {avg }}-\rho_{i}\right) \cdot g \cdot H
$$

Combining of Equations (1)-(5), the natural wind velocity inside the tunnel can be obtained as:

$$
v_{i}=\sqrt{2 \times \frac{P_{e n}-P_{e x}-2 \times \rho_{i} \cdot g \cdot H+0.35 \times\left[\rho_{e n} \cdot\left(v_{\alpha e n} \cdot \cos \alpha_{e n}\right)^{2}-\rho_{e x} \cdot\left(v_{\alpha e x} \cdot \cos \alpha_{e x}\right)^{2}\right]+\rho_{\text {avg }} \cdot g \cdot H}{\rho_{i} \cdot\left(\lambda_{r} \cdot \frac{L}{D_{r}}+\xi_{e}+1\right)}}
$$

\subsubsection{Calculation Methods of the Natural Wind Velocity in the Tunnel with Inclined Shafts}

Calculation Method of Ultra-Static Pressure Difference and Dynamic Pressure in the Tunnels with Shafts

As shown in Figure 2, point 3 at the shaft is set as the calculation reference point of ultra-static pressure. The ultra-static pressure difference relative to point 1 at the lower tunnel entrance, point 2 at the higher tunnel entrance and point 3 at the inclined shaft exit are $\Delta P_{u 1}, \Delta P_{u 2}$ and $\Delta P_{u 3}$, respectively $\left(\Delta P_{u 3}=0\right)$. With the ultra-static pressure difference, the air in the tunnel and the shaft starts to flow 
and finally becomes steady. At this time, the ultra-static pressure differences in the tunnel will be stable values. When the airflow is stable, $\Delta P_{u 4}{ }^{\prime}$ stands for the sum of the ultra-static pressure $\Delta P_{u 4}$ and dynamic pressure $h_{v}$. Without the pressure losses of conflux and split flow taken into account, the value of $\Delta P_{u 4}{ }^{\prime}$ at the cross sections $\mathrm{a}-\mathrm{a}^{\prime}, \mathrm{b}-\mathrm{b}^{\prime}$ and $\mathrm{c}-\mathrm{c}^{\prime}$ will be equal. Then, the pressure difference of the sum of $\Delta P_{u 4}$ and $h_{v}$ at the two tunnel ends and the inclined shaft exit with respect to the inclined shaft bottom are obtained (hereinafter referred to as differential pressure). When the airflow $Q_{i}(i=1,2,3)$ flows in Node 4 , the value of $Q_{i}$ is positive, otherwise, it is negative.

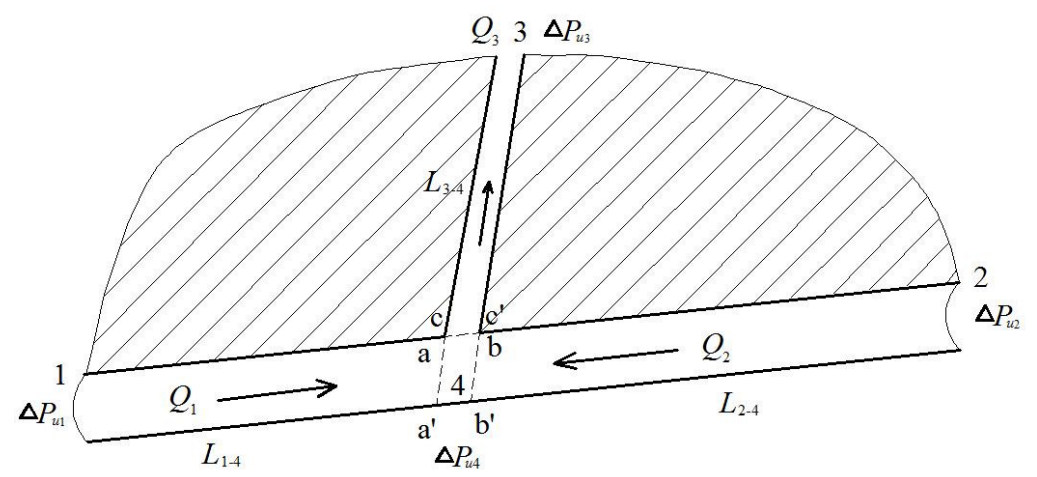

Figure 2. Calculation method of natural wind in the tunnel with shafts.

The laws of airflow resistance are shown as Equations (7)-(9).

$$
\begin{aligned}
& \Delta P_{u 1}{ }^{\prime}-\Delta P_{u 4}{ }^{\prime}=\left(R_{1}+R_{1}{ }^{\prime}\right) \cdot Q_{1} \cdot\left|Q_{1}\right| \\
& \Delta P_{u 2}{ }^{\prime}-\Delta P_{u 4}{ }^{\prime}=\left(R_{2}+R_{2}{ }^{\prime}\right) \cdot Q_{2} \cdot\left|Q_{2}\right| \\
& \Delta P_{u 3}{ }^{\prime}-\Delta P_{u 4}{ }^{\prime}=\left(R_{3}+R_{3}{ }^{\prime}\right) \cdot Q_{3} \cdot\left|Q_{3}\right|
\end{aligned}
$$

where $R_{i}$ and $R_{i}{ }^{\prime}(i=1,2,3)$ is the frictional resistance and the local resistance of the tunnel, respectively. For Node 1 , in the ventilation network, when the air density changes little, the air quantity flowing in Node $i$ is equal to that flowing out of Node $i$, i.e., the algebraic sum at any node is zero, as shown in Equations (10) and (11).

$$
\begin{gathered}
Q_{1}+Q_{2}+Q_{3}=0 \\
Q_{i}=S_{i} \cdot v_{i}\{i=1,2,3\}
\end{gathered}
$$

As a middle node in the ventilation system, the air flows in and out. When the air flows from Node $i$ into Node $4, \Delta P_{u 4}{ }^{\prime}<\Delta P_{u i}$. The calculation steps are listed as follows:

1. Suppose $\Delta P_{u 4}{ }^{\prime}=\min \left(\Delta P_{u 1}{ }^{\prime}, \Delta P_{u 2}{ }^{\prime}, \Delta P_{u 3}{ }^{\prime}\right)$.

2. Insert $\Delta P_{u 4}{ }^{\prime}$ into Equations (7)-(9), then get the air quantities $Q_{1}, Q_{2}$ and $Q_{3}$.

3. Calculate the sum of $Q_{1}, Q_{2}$ and $Q_{3}$, if $Q_{1}+Q_{2}+Q_{3}<\varepsilon$, the calculation is over. $\varepsilon$ is the control accuracy and its value is very small, such as 0.1 . The calculated $Q_{1}, Q_{2}$ and $Q_{3}$ are the solutions of the calculation. Otherwise, conduct Step 4.

4. Suppose $\Delta P_{u 4}{ }^{\prime}=\Delta P_{u 4}{ }^{\prime}+0.01$, repeat Steps 2 and 3. The value of $\Delta P_{u 4}{ }^{\prime}$ will not be larger than all of $\Delta P_{u 1}{ }^{\prime}, \Delta P_{u 2}{ }^{\prime}$ and $\Delta P_{u 3}{ }^{\prime}$, so another end condition of the calculation is $\Delta P_{u 4}{ }^{\prime}=\max \left(\Delta P_{u 1}{ }^{\prime}, \Delta P_{u 2}{ }^{\prime}, \Delta P_{u 3}{ }^{\prime}\right)$. When $\Delta P_{u 4}{ }^{\prime}=\max \left(\Delta P_{u 1}{ }^{\prime}, \Delta P_{u 2}{ }^{\prime}, \Delta P_{u 3}{ }^{\prime}\right)$, the calculation will end with no results.

This calculation can be used for the air volume of each section in the tunnel. However, when it involves a cyclic process, the calculation method is no longer appropriate. 
Calculation Method of Thermal-Potential Pressure Difference in the Tunnels with Shafts

Suppose that the air temperature in the tunnel is $T_{3}$, the temperature at the tunnel entrance, exit and (inclined) shaft exit are $T_{1}, T_{2}$ and $T_{4}$, respectively. The corresponding air densities are $\rho_{3}, \rho_{1}, \rho_{2}$ and $\rho_{4}$. The elevation of the tunnel entrance, the exit, the shaft bottom and the shaft exit are $H_{1}, H_{2}$, $H_{3}$ and $H_{4}$, as shown in Figure 3.

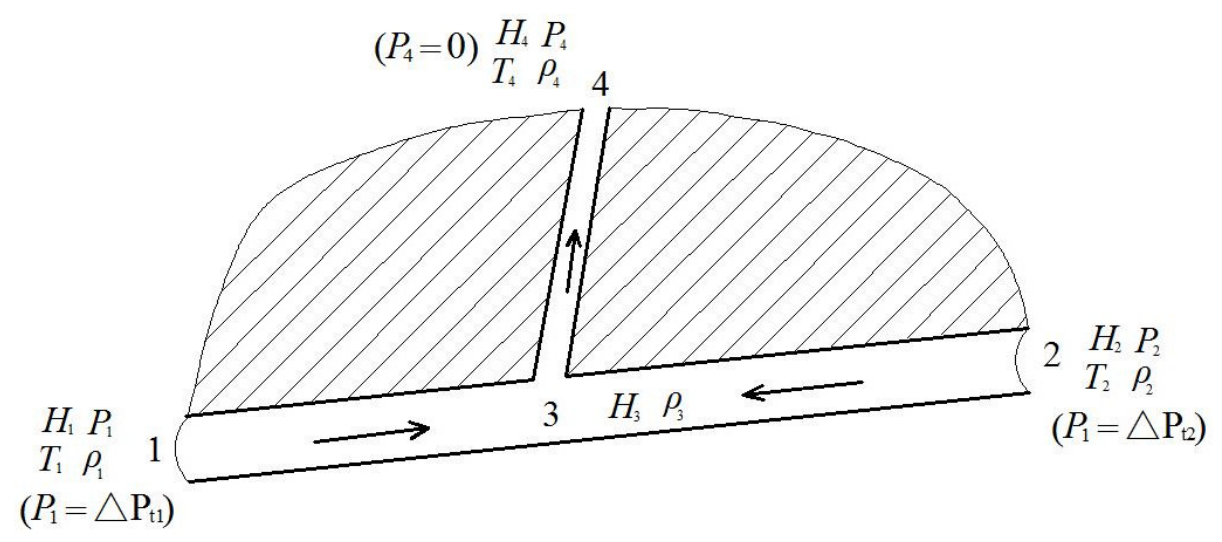

Figure 3. Calculation method of thermal-potential pressure difference with shafts.

Assume that the average air density out of the tunnel is $\rho_{a v g}$, Equations (11) and (12) would find thermal-potential pressure difference:

$$
\begin{aligned}
& \Delta P_{t 1}=\rho_{a v g 1} \cdot g \cdot H_{1-4}-\rho_{i} \cdot g \cdot H_{1-3}-\rho_{i} \cdot g \cdot H_{3-4} \\
& \Delta P_{t 2}=\rho_{a v g 2} \cdot g \cdot H_{2-4}-\rho_{i} \cdot g \cdot H_{2-3}-\rho_{i} \cdot g \cdot H_{3-4}
\end{aligned}
$$

In the static atmosphere, the difference of barometric pressures between point $m$ and point $n$ is the static pressure difference. If the air density in the tunnel is equal to the air density out of the tunnel, the ultra-static pressure of point $m$ relative to point $n$ is zero, the air inside will not circulate. On the contrary, if air flows in the tunnel, the driving force of air in the tunnel is the thermo-potential difference only, whose effect is equal to ultra-static pressure. As a result, the thermo-potential pressure difference can be treated as the ultra-static pressure difference. The equivalence results are shown in Figure 3.

According to the ultra-static pressure difference calculation method, we can obtain the air quantity $\left(Q_{i}\right)$ of each section under the influence of thermo-potential pressure difference. The principle is the same for tunnels with many shafts, but multiple circulations are required, the circulation frequency is equal to the number of shafts.

Generally speaking, an extra-long highway tunnel will be equipped with several shafts or inclined shafts. Therefore, the calculation method of the ultra-static pressure difference, the thermal-potential pressure difference and the ventilation-wall pressure difference of each tunnel section are obtained. Insert the wind pressure value calculated into Equation (6), and we can get the natural wind velocity of each section in the segmented longitudinal ventilation tunnel.

\subsubsection{Additional Explanation about the Calculation Methods of the Natural Wind Velocity in the Tunnel}

What needs to be made clear is that the pressure induced by vehicles $P_{t}$, the pressure induced by ventilation equipment $P_{v}$ and the pressure loss due to wind resistance $\Delta P$ (including local pressure loss $\Delta P_{\varepsilon i}$ and frictional pressure loss $\Delta P_{r}$ ) are all important pressure drivers in operating tunnels. The calculation methods of the three pressure drivers were introduced in many references such as Chinese specification for design of ventilation and lighting of highway tunnel [4]. The values of loss coefficients 
$\lambda_{r}$ and $\xi_{e}$ were also set as the specification required. However, when calculating the natural wind velocity, the pressure resulted from cars and ventilation equipment is not within the research scope.

The air temperature inside a road tunnel will be affected by the geothermal heat from the tunnel wall and the exhaust gas from the road vehicles. After the endothermic process of expansion, the air density declines and the airflow increases accordingly. As a result, the natural wind velocity in the tunnel will increase to a certain degree which improves natural ventilation. When considering the slope in a tunnel without (inclined) shaft, the heated air will tend to flow to the upper portal of the tunnel. Therefore, tunnel ventilation may also benefit from the heated air if the wind direction is from the lower portal to the upper portal.

For tunnels without (inclined) shaft, the pressure difference between portals is equal to the sum of ultra-static pressure and the air mass inside the tunnel as shown in Equation (3). The value of thermo-potential pressure depends on the value of height difference between portals and air density difference according to Equation (5). Generally, when $\rho_{\text {average }}$ is approximately $\rho_{0}$, the value of thermo-potential pressure will be far smaller than the pressure difference between portals. Then, the pressure difference between portals will be the main driving factor of airflow in the tunnel.

As to the tunnels without large altitude difference between portals, the value of thermo-potential pressure will decline accordingly. The situation of the tunnels with (inclined) shafts is quite complicated and certain principles should be given further research.

\subsection{Validation on the Calculation Methods of Natural Wind}

\subsubsection{Overview of the Nibashan Tunnel}

The Nibashan Tunnel is located in the Da'Xiang Ridge of Ya'an, China. The tunnel is 10,007 $\mathrm{m}$ in length and the area of the tunnel cross section is $64.11 \mathrm{~m}^{2}$. The average altitude of the Nibashan Tunnel is $3118 \mathrm{~m}$; the altitude difference between the tunnel portals is $15 \mathrm{~m}$. Two shafts, named Lugu shaft and Ya'an shaft, are designed to improve the ventilation in the Nibashan Tunnel. Lugu shaft and Ya'an shaft divide the Nibashan Tunnel into three sections. The number of fans in the tunnel is shown in Table 1.

Table 1. Fan configuration in the Nibashan Tunnel.

\begin{tabular}{|c|c|c|c|c|c|c|c|c|}
\hline \multirow{2}{*}{ Line } & \multirow{2}{*}{ Index } & \multirow{2}{*}{ Section 1} & \multirow{2}{*}{ Section 2} & \multirow{2}{*}{ Section 3} & \multicolumn{2}{|c|}{ Supply Shaft } & \multicolumn{2}{|c|}{ Exhaust Shaft } \\
\hline & & & & & Ya'an & Lugu & Ya'an & Lugu \\
\hline Left line & $\begin{array}{c}\text { Number } \\
\text { Power }\end{array}$ & $\begin{array}{c}6 \\
37 \mathrm{~kW}\end{array}$ & $\begin{array}{c}17 \\
37 \mathrm{~kW}\end{array}$ & $\begin{array}{c}0 \\
37 \mathrm{~kW}\end{array}$ & 512 kW & $141 \mathrm{~kW}$ & $97 \mathrm{~kW}$ & $136 \mathrm{~kW}$ \\
\hline $\begin{array}{l}\text { Right } \\
\text { line }\end{array}$ & $\begin{array}{c}\text { Number } \\
\text { Power }\end{array}$ & $\begin{array}{c}6 \\
37 \mathrm{~kW}\end{array}$ & $\begin{array}{c}13 \\
37 \mathrm{~kW}\end{array}$ & $\begin{array}{c}0 \\
37 \mathrm{~kW}\end{array}$ & $640 \mathrm{~kW}$ & $188 \mathrm{~kW}$ & $116 \mathrm{~kW}$ & $138 \mathrm{~kW}$ \\
\hline
\end{tabular}

The strike direction of the Nibashan tunnel is NE-SW. The angle between the main wind direction at the tunnel portal and the central axis of the tunnel is big. The wind velocity outside the portal is small. The effect of airflow in the external environment on the wind velocity in the tunnel is quite marginal.

\subsubsection{Field Tests in the Nibashan Tunnel}

In the design phase of the Nibashan Tunnel, four automatic meteorological stations were installed, as shown in Figure 4. The stations mainly measured wind velocity, wind direction, atmospheric pressure, temperature and humidity.

These parameters were automatically measured and stored every 30 minutes. From 18 March 2008 to 16 July 2009, the stations monitored the meteorological conditions outside the Nibashan Tunnel for 485 days and stored 14,776 groups of data. Metrological properties of the instruments are listed in Table A1. The wind velocity, pressure and temperature distribution graphs in the four stations were obtained through statistical analysis, which are shown in Figures A1-A3. 


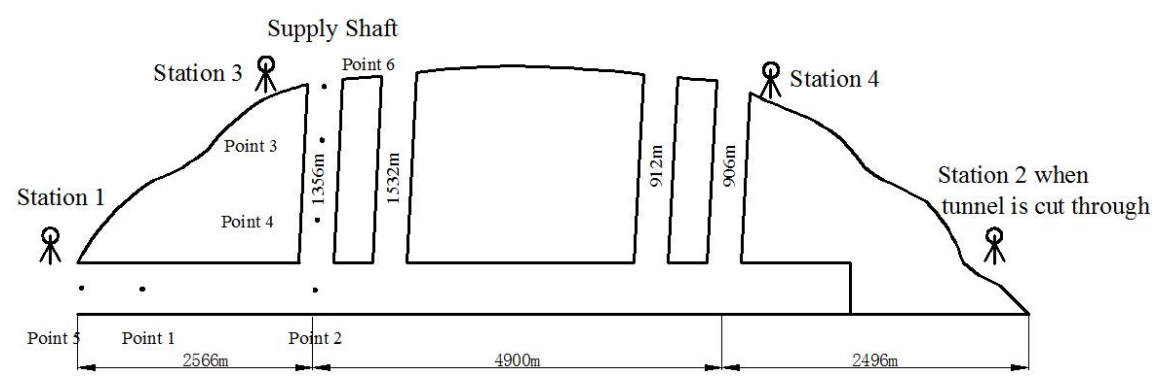

(a)

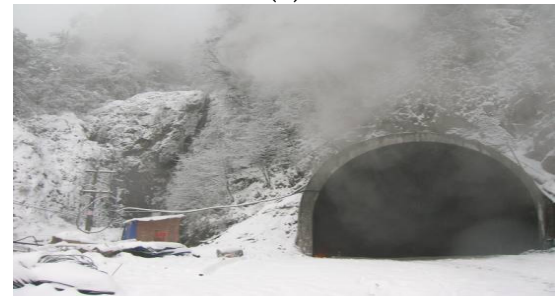

(b)

Figure 4. (a) Field test point arrangement; and (b) the portal of the Nibashan Tunnel.

Based on the data from the meteorological stations of the Nibashan Tunnel, researchers calculated the wind velocity in the tunnel and the inclined shafts with the theoretical calculation method described in Section 2.1. In order to validate this calculation method, researchers also carried out a field test on the natural wind velocity inside the tunnel. When the whole tunnel was not cut through but the inclined shafts of Lugu section were done, researchers set six test points inside the main tunnel, at the main tunnel entrance and exit, inside the inclined shaft and at the inclined shaft mouth for testing. Then, the pressure, wind velocity, temperature and humidity in the inclined shafts of Lugu section were obtained. The test points are shown in Figure 4 . The field tests of wind speed in the tunnel were conducted from 15:00 to 17:00 on 8 August 2008. Researchers collected 24 sets of wind speed data for each test point. As the results show in Table 2, the indexes indicate that the theoretical calculation method proposed in this paper is suitable for an extra-long tunnel.

Table 2. Analysis of the natural wind velocity.

\begin{tabular}{ccccc}
\hline Test Point & $\mathbf{1}$ & $\mathbf{2}$ & $\mathbf{3}$ & $\mathbf{4}$ \\
\hline Average tested wind speed (m/s) & 0.18 & 0.21 & 4.29 & 4.49 \\
Average calculation wind speed (m/s) & 0.2 & 0.2 & 4.4 & 4.4 \\
Absolute error (m/s) & 0.02 & -0.01 & 0.11 & -0.09 \\
Coefficient of determination & 0.83 & 0.91 & 0.83 & 0.77 \\
Root mean square error & 0.14 & 0.09 & 0.27 & 0.22 \\
Willmott's index of agreement & 0.89 & 0.95 & 0.92 & 0.88 \\
\hline
\end{tabular}

\subsection{Utilization Modes of the Natural Wind}

In order to make full use of the regular and observable natural wind for tunnel ventilation, it is necessary to take use of the natural wind as the driving force for ventilation. The control principle of the ventilation using natural wind is the main natural wind direction. The traffic wind direction should be taken into consideration if discussing the wind direction of the mechanical ventilation.

\subsubsection{Control Principles of the Natural Wind}

The natural wind direction may or may not be the same as the ventilation direction. In the former case, the natural wind in the tunnel contributes to the tunnel ventilation. If the wind velocity is higher than the design wind velocity, natural wind can fully meet the requirement of the tunnel 
ventilation alone. If not, mechanical ventilation will be necessary to improve the tunnel ventilation effect. The number of the operating fans can be calculated based on the natural wind resistance of zero. In the latter case, the natural wind is regarded as the resistance. The modes of natural wind utilization are shown in Table 3.

Table 3. Control strategy.

\begin{tabular}{cccc}
\hline Strategy & $V_{\boldsymbol{n}}(\mathrm{m} / \mathbf{s})$ & Natural Wind Function & Opening Jet Fans \\
\hline A & $V_{n}>V_{0}$ & Driving Force & None \\
B & $0<V_{n}<V_{0}$ & Driving Force & Some \\
C & $V_{n}<0$ & Resistance & All \\
\hline
\end{tabular}

\subsubsection{The Natural Wind Control Modes}

As implied in Section 2.3.1, the key of natural wind utilization is to master the natural wind direction distribution. The distribution statistic of natural wind direction in the Nibashan tunnel was made. When the natural wind directions and wind velocities are calculated, the natural wind distribution in the left line, the right line and the shafts of the Nibashan Tunnel can be systematically analyzed. Then, researchers set about formulating the control modes of natural wind according to the distribution probability.

The division of control modes is based on natural wind probability statistic. Researchers divided the main tunnel into three sections. The natural wind direction in each section may or may not be the same as the ventilation direction. Considering the four shafts, there will be 128 possible combination cases of natural wind directions in theory.

According to the statistic results, 18 combination modes exist in fact. When the natural wind velocity is small, the ventilation effect of natural wind is quite small. Thus, if the natural wind velocity in the main tunnel is below $0.5 \mathrm{~m} / \mathrm{s}$, the natural wind in the main tunnel can be ignored. The combination modes with low probability are also removed in the study. As a result, eight modes remain for the right line and the left line of the Nibasahn Tunnel.

When the modes of the natural wind in the Nibashan Tunnel are determined, the natural wind resistance of the tunnel is clear. Aside from the natural wind resistance, the resistances in the Nibasahn Tunnel also include the traffic wind resistance and frictional resistance [4]. The power of fans in each section will be confirmed according to the resistance. Actual calculation methods of the resistance as well as the fan layout are based on the specification [4]. The drawing of how the fans are connected to the sensors and the control center is shown in Figure 5.

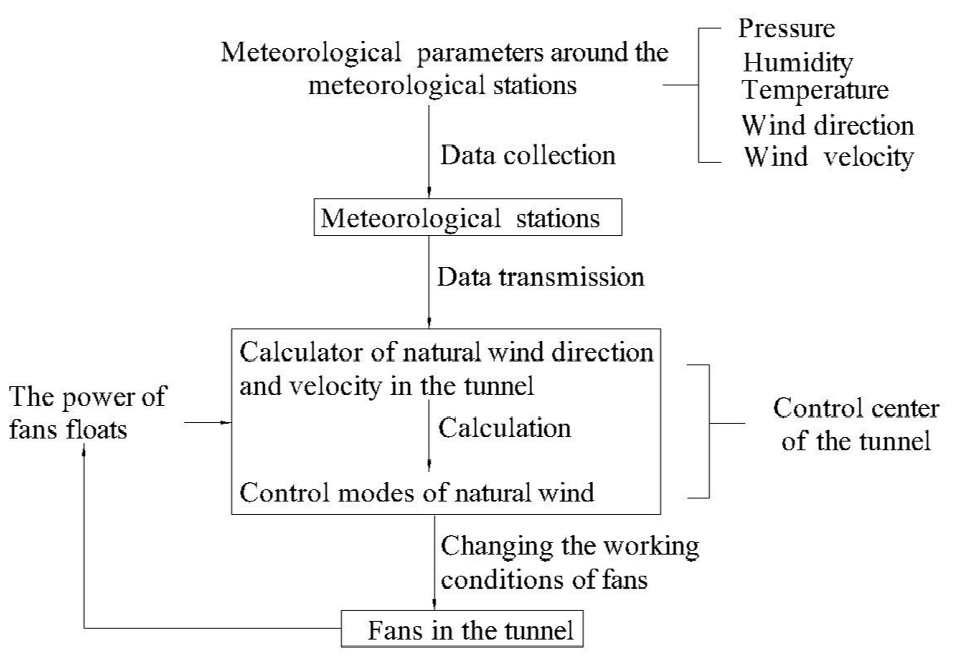

Figure 5. Diagram of the connections among fans, meteorological stations and control centers of the tunnel. 


\section{Results and Discussion}

The energy-saving network system applied in the Nibashan Tunnel, simple but effective, is similar to fuzzy logic control system. Researchers established a complete set of wind velocity calculation methods and changed the control strategy. For the fuzzy logic control system, the design wind velocity in the tunnel is determined by CO concentration generally. CO concentration is involved in many factors such as traffic volume, so the wind velocity in the tunnel will keep changing accordingly $[15,32]$. However, for the energy-saving network system in the paper, the design velocity in the tunnel is determined due to statistics of the meteorological data. The air quality in the tunnel can be guaranteed as long as the actual wind velocity in the tunnel is larger than the design velocity.

\subsection{Design Velocity of Natural Wind}

Chinese specifications for ventilation and lighting design of highway tunnel [4] specify that the natural wind velocity can be determined by the meteorological data and the tunnel parameters. For most tunnels, the natural wind velocity is set as $2-3 \mathrm{~m} / \mathrm{s}$. As to the Zhongnan Mountains, there were three-day field tests for deciding the natural wind velocity $[33,34]$. However, at this was a short time for monitoring, the data are not abundant enough to reflect the wind velocity rules inside the tunnel, especially for tunnels located in the climate separation zones.

With the calculation correlation utilizing the natural wind velocity inside the Nibashan Tunnel, the annual patterns of the natural wind inside the tunnel were figured out (illustrated by the case of January). The main tunnel and shafts of the Nibashan Tunnel constitute a simple ventilation system. Figure 6 shows how the wind velocity trend changes in the main tunnel on 30 December 2008. One may see that the trends in each section vary greatly. In the first section, the wind direction is negative and the wind velocity is large (the maximum velocity is $5 \mathrm{~m} / \mathrm{s}$ ). In the second and third section, the wind direction changes often and the wind velocity is relatively small. Therefore, the designed wind velocity of $2-3 \mathrm{~m} / \mathrm{s}$, which is recommended in the specification, does not agree with the wind velocity features of the Nibashan Tunnel.

In the case of the Nibashan Tunnel, set the section from Lugu portal to the exhaust shaft \#1 as Section 1; the section from supply shaft \#1 to the exhaust \#2 as Section 2; and the section from supply shaft \#2 to Ya'an portal as Section 3. With calculation, it can be known that the main natural wind direction is from Lugu to Ya'an. The annual probabilities of each section are $63.2 \%$ for the first section, $60.8 \%$ for the second section, and $61.5 \%$ for the third section. The situation in the inclined shafts is: blowing-in from the inclined shaft at Ya'an portal, with annual probability of $62.0 \%$; and blowing-in from the inclined shaft at Lugu portal, with annual probability of $53.9 \%$. The natural wind direction inside the tunnel is shown in Figure 7.

According to the meteorological data in the whole year, it can be concluded that: the main wind direction in the first section is negative and at a velocity of $2.4 \mathrm{~m} / \mathrm{s}$; the main wind direction in the second section is positive and at a velocity of $2.4 \mathrm{~m} / \mathrm{s}$; and the main wind direction in the third section is positive and at a velocity of $1.2 \mathrm{~m} / \mathrm{s}$, as shown in Figure A4.

The concept of wind velocity with guarantee rate is employed in the study. It refers to the wind velocity ensuring a certain probability when natural wind is considered as resistance. When natural wind velocity is below the velocity with the guarantee rate, the ventilation system can meet the requirements of operation. To ensure that there is larger probability for the ventilation system to meet the operational needs, the authors take $98 \%$ and $95 \%$ as guarantee rates of design wind velocity, as depicted in Table 4. 


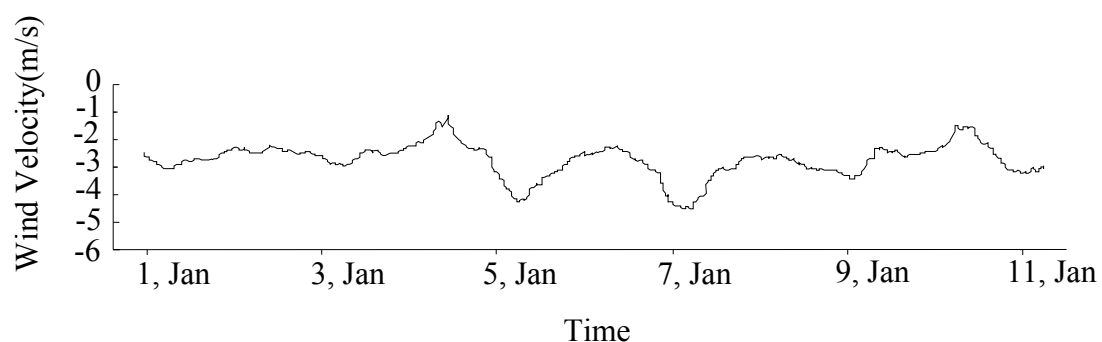

(a)

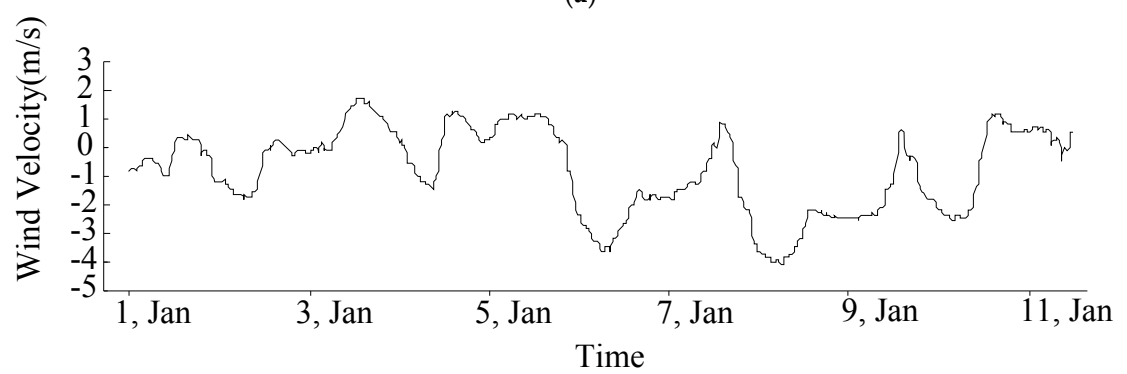

(b)

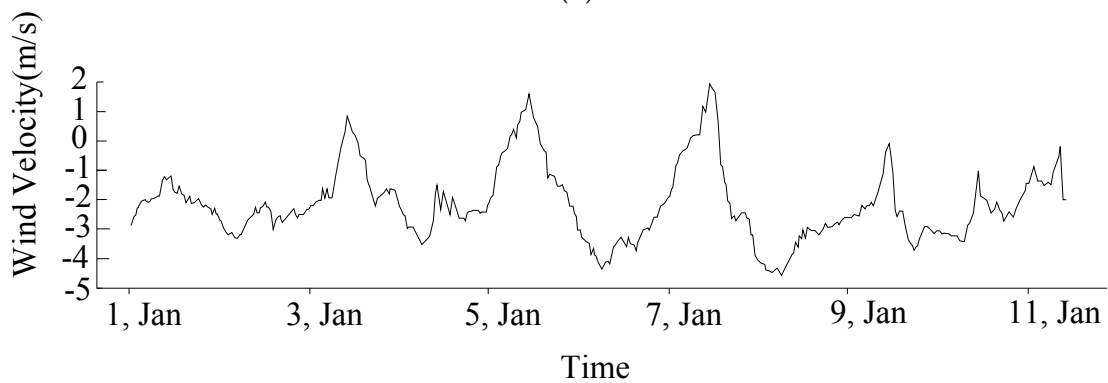

(c)

Figure 6. Wind velocity in the main tunnel in January: (a) wind velocity of Section 1; (b) wind velocity of Section 2; and (c) wind velocity of Section 3.

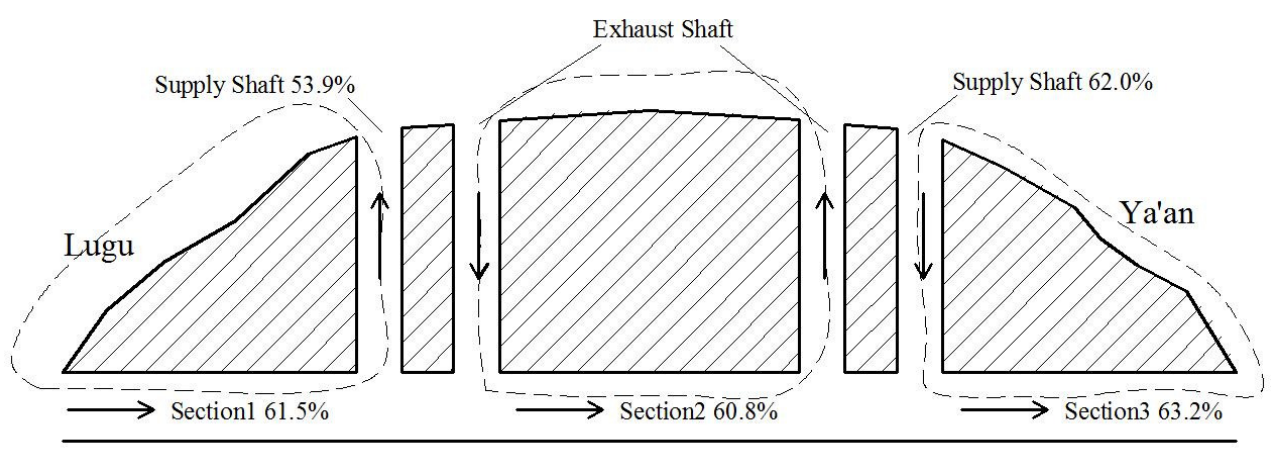

Figure 7. Main wind direction in the sections of the Nibashan Tunnel.

Table 4. Guaranteed wind speeds in the Nibashan Tunnel.

\begin{tabular}{cccc}
\hline Guarantee Rate & Section & Right Line & Left Line \\
\hline \multirow{2}{*}{$98 \%$} & Section 1 & $2.17 \mathrm{~m} / \mathrm{s}$ & $3.32 \mathrm{~m} / \mathrm{s}$ \\
& Section 2 & $3.46 \mathrm{~m} / \mathrm{s}$ & $3.05 \mathrm{~m} / \mathrm{s}$ \\
& Section 3 & $2.94 \mathrm{~m} / \mathrm{s}$ & $2.41 \mathrm{~m} / \mathrm{s}$ \\
\hline \multirow{2}{*}{$95 \%$} & Section 1 & $2.01 \mathrm{~m} / \mathrm{s}$ & $3.14 \mathrm{~m} / \mathrm{s}$ \\
& Section 2 & $3.08 \mathrm{~m} / \mathrm{s}$ & $2.67 \mathrm{~m} / \mathrm{s}$ \\
& Section 3 & $2.69 \mathrm{~m} / \mathrm{s}$ & $2.23 \mathrm{~m} / \mathrm{s}$ \\
\hline
\end{tabular}




\subsection{Division of Control Period}

Period control is about dividing the whole year into different control periods. According to the natural wind characters, researchers obtained the most unfavorable conditions within control period through calculation. The better the period division is, the more precise the period control is, and the higher the energy efficiency is.

\subsubsection{Daily Control Strategy}

Since there are large temperature differences between day and night, the control periods can be different between day and night. In line with the natural wind velocity vs. time diagram, time is split by two lines, namely the design wind velocity and wind velocity that are equal to zero. The period statistics is made depending on the split. The control period is determined as day (from 07:00 to 19:00) and night (from 19:00 to 07:00) in accordance with statistics results. Figure 8 shows the daily control strategies in different sections of the left tunnel in January.

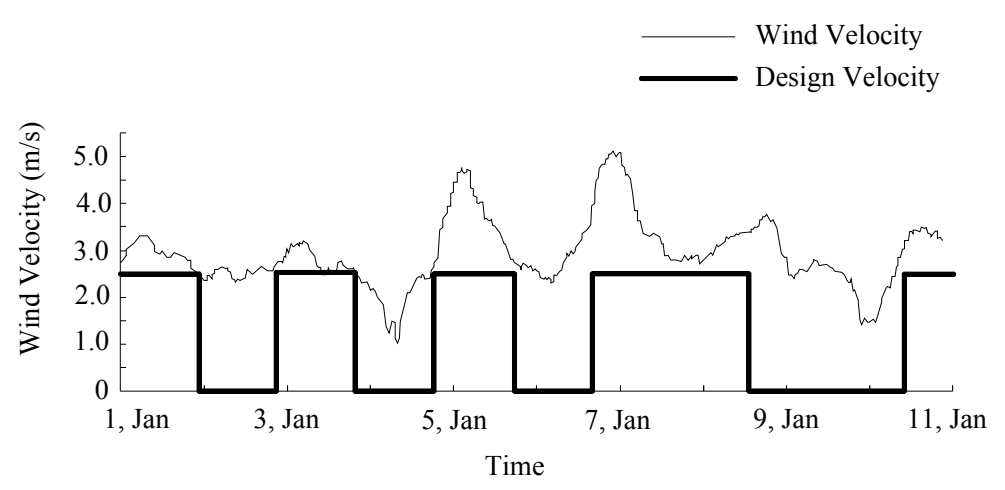

(a)

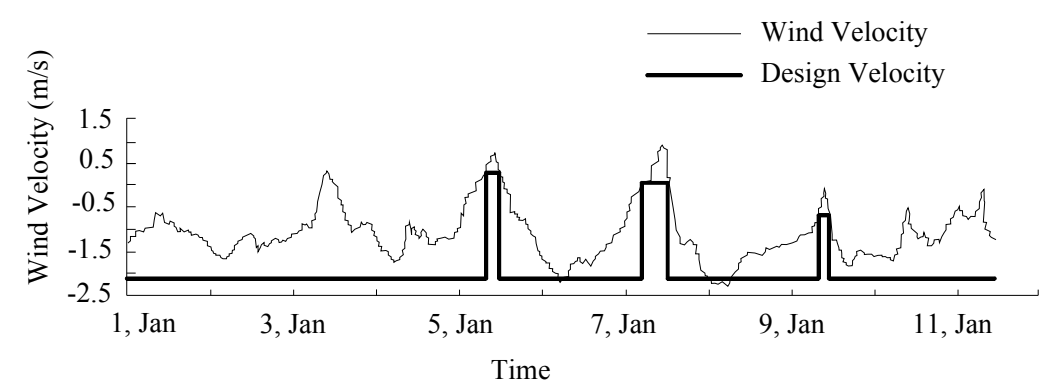

(b)

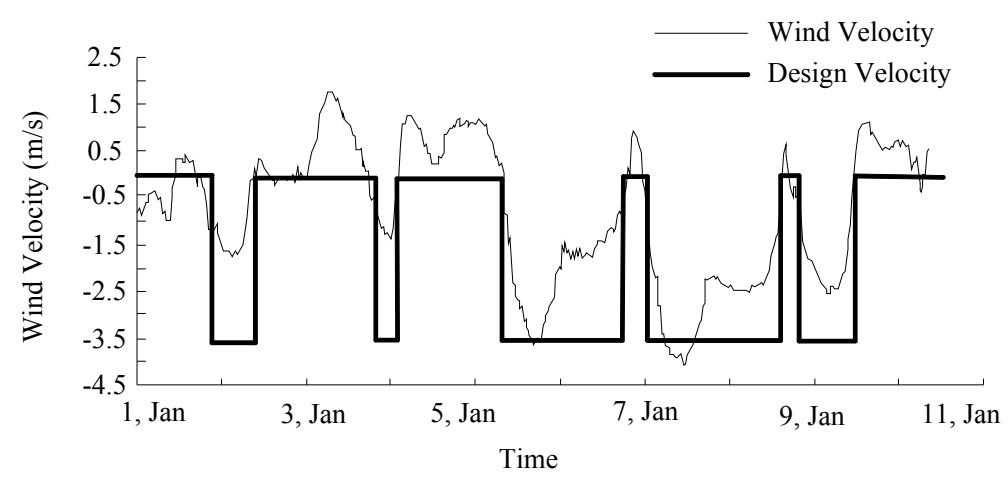

(c)

Figure 8. Control strategy by day: (a) control strategy in Section 1; (b) control strategy in Section 2; and (c) control strategy in Section 3. 
According to the natural wind control modes, the ventilation mode of the left tunnel in January is determined as shown in Table 5.

Table 5. Control strategy of the Nibashan Tunnel (left line).

\begin{tabular}{ccccc}
\hline \multirow{2}{*}{ Time } & \multirow{2}{*}{ Ventilation Mode } & \multicolumn{3}{c}{ Working Conditions } \\
\cline { 3 - 5 } & & Section 1 & Section 2 & Section 3 \\
\hline Daytime & 18 & SZ-1-B & SZ-1-C & SZ-1-C \\
Night & 9 & SZ-1-A & SZ-1-C & SZ-1-C \\
\hline
\end{tabular}

Note: $S$ stands for jet fan; $Z$ stands for left line; 1,2 and 3 is the section number; $A, B$ and $C$ is the control strategy.

\subsubsection{Hourly Control Strategy}

Depending on the distribution of natural wind throughout the year, the hourly control strategies can be different in control duration. One hour, two hours, three hours, four hours, five hours and six hours may be feasible duration for the control strategies. Taking the control strategy of one hour operating condition as an example, the ventilation mode of the left line of the Nibashan Tunnel is obtained by analyzing various periods of natural wind throughout the year. Figure 9 shows the wind velocity variation trend and design wind velocity of the left line.

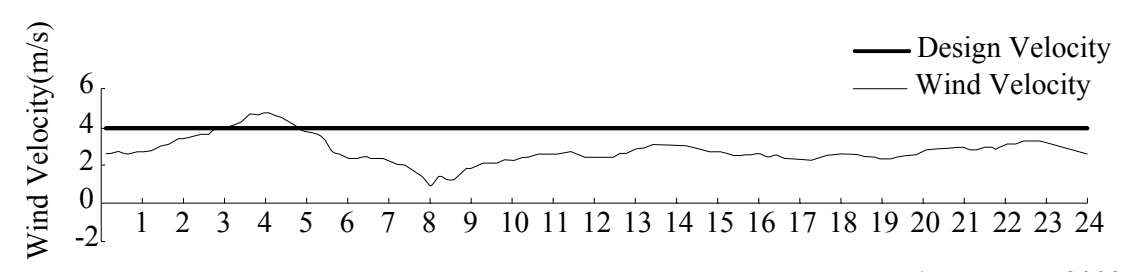

(a)

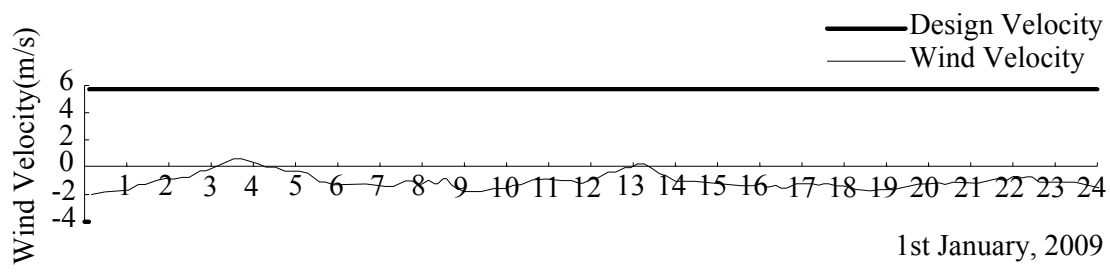

(b)

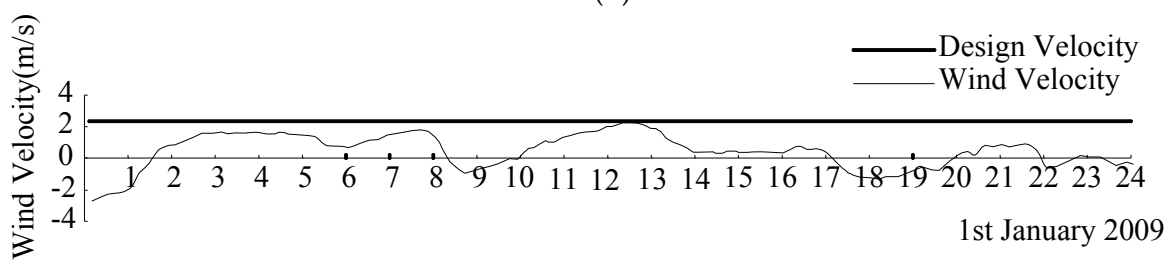

(c)

Figure 9. Control strategies by hour: (a) control strategy in Section 1; (b) control strategy in Section 2; and (c) control strategy in Section 3.

\subsection{Energy-Saving Analysis}

For most short road tunnels, only few fans are installed in the tunnels and the mechanical ventilation is not used as much as long tunnels. Thus, ventilation system occupies a small proportion (10-35\%) of the total energy consumption compared to the lighting system [35]. However, for extra-long road tunnels, the effect of natural wind on tunnel ventilation is rarely sufficient for sustaining good air quality without jet fans of large power. For example, the Nibashan Tunnel in Daxiang Range is $10 \mathrm{~km}$ long. The installed power of its ventilation system is $6500 \mathrm{~kW}$. The electricity costs will be 3.06 million 
dollars annually if the system operates eight hours a day, which takes up $65 \%$ of its operation energy consumption (only $25 \%$ for illumination).

During the tunnel operation, the ventilation costs account for a large proportion of the overall tunnel operation costs. A reasonable fan control strategy, which takes full advantages of the natural wind dynamics, will lower the operation costs greatly [36,37]. The strategy of combining natural ventilation with mechanical ventilation was implemented in the Yuanliangshan Tunnel empirically, which has halved the number of jet fans in the tunnel but maintained the same ventilation effect [38].

\subsubsection{Energy Saving at Different Wind Velocity}

Based on the traffic volume of the left line in the Nibashan Tunnel in 2010, the power of fans at different natural wind velocities was calculated. As the results listed in Table 6 show, the increase of the natural wind velocity will remarkably increase the energy consumption. As the wind resistance correlates with the square of the wind velocity, the wind resistance will obviously increase with the wind velocity growth. Power of jet fans rises with the increase of wind resistance accordingly.

Table 6. Fan power at different velocities.

\begin{tabular}{ccccc}
\hline $\begin{array}{c}\text { Natural Wind } \\
\text { Velocity } \\
(\mathbf{m} / \mathbf{s})\end{array}$ & $\begin{array}{c}\text { Resistance of } \\
\text { Natural Wind } \\
(\mathbf{k P a})\end{array}$ & $\begin{array}{c}\text { Other Resistance } \\
\mathbf{( k P a )}\end{array}$ & $\begin{array}{c}\text { Percentage of } \\
\text { Natural Wind } \\
\text { Resistance }\end{array}$ & $\begin{array}{c}\text { Total Power } \\
\mathbf{( k W )}\end{array}$ \\
\hline 0 & 0.00 & 51.86 & 0 & 8.78 \\
2 & 18.45 & 51.86 & $26.24 \%$ & 41.26 \\
4 & 73.80 & 51.86 & $58.73 \%$ & 138.69 \\
6 & 166.06 & 51.86 & $76.2 \%$ & 301.08 \\
8 & 295.22 & 51.86 & $85.06 \%$ & 820.72 \\
\hline
\end{tabular}

Considering the natural wind velocity and direction, there were favorable and unfavorable conditions. If the natural wind can be exploited as power properly, much energy will be saved. Based on the traffic volume of the Nibashan Tunnel in 2010, the power of fans was calculated when natural wind is at $2.5 \mathrm{~m} / \mathrm{s}$ and at a velocity with guarantee rat of $95 \%$. The results are shown in Table 7 .

Table 7. Fan power in different design wind velocity.

\begin{tabular}{|c|c|c|c|c|c|c|c|c|c|}
\hline \multirow[t]{2}{*}{$\begin{array}{l}\text { Design Wind } \\
\text { Velocity }\end{array}$} & \multirow[t]{2}{*}{ Line } & \multicolumn{2}{|c|}{ Section $1(\mathbf{k W})$} & \multicolumn{3}{|c|}{ Section $2(\mathbf{k W})$} & \multicolumn{2}{|c|}{ Section $3(\mathbf{k W})$} & \multirow{2}{*}{$\begin{array}{c}\text { Total Power } \\
(\mathbf{k W})\end{array}$} \\
\hline & & Jet Fans & $\begin{array}{l}\text { Axial Flow } \\
\text { Fans }\end{array}$ & $\begin{array}{l}\text { Supply } \\
\text { Fans }\end{array}$ & Jet Fans & $\begin{array}{l}\text { Exhaust } \\
\text { Fans }\end{array}$ & Jet Fans & $\begin{array}{c}\text { Axial flow } \\
\text { Fans }\end{array}$ & \\
\hline \multirow{3}{*}{$2.5 \mathrm{~m} / \mathrm{s}$} & Left & 148 & 24 & 193 & 296 & 45 & 0 & 122 & \multirow{3}{*}{1600} \\
\hline & Right & 148 & 22 & 157 & 296 & 32 & 0 & 117 & \\
\hline & Total & 296 & 46 & 350 & 592 & 77 & 0 & 239 & \\
\hline \multirow{2}{*}{$\begin{array}{c}95 \% \text { guaranteed } \\
\text { probability }\end{array}$} & Right & 74 & 22 & 157 & 296 & 32 & 0 & 117 & \multirow[t]{2}{*}{1748} \\
\hline & Total & 222 & 46 & 350 & 666 & 77 & 148 & 239 & \\
\hline
\end{tabular}

From the results illustrated in Table 7, the installed power calculated by the wind velocity with the guarantee rate of $95 \%$ is larger than that calculated by $2-3 \mathrm{~m} / \mathrm{s}$ (as recommended in specifications). However, setting the design wind velocity at the velocity with a guarantee probability needs fewer operating jet fans. The ventilation effect is also better than traditional ventilation with the recommended wind velocity in specifications. Assuming the electricity price is 0.18 dollar per $\mathrm{kWh}$, 0.35 million dollars will be saved in tunnel ventilation every year.

\subsubsection{Energy Saving with Different Control Strategies}

Division of control period is vital for ventilation energy saving in extra-long tunnels. The shorter the control period is, the closer the natural wind velocity will be to the actual condition. Based on the 
daily control strategy and the wind velocity with a guarantee rate of $95 \%$, the power of fans and the corresponding energy saving effect are given in Table 8. The energy saving effect in July and August is the most obvious, totally $410.5 \mathrm{~kW}$ is saved in July and August, while the energy saving in January and December is quite little. It can be explained by the natural wind distribution of the Nibashan Tunnel in these months. The wind resource in summer is richer than in winter. Thus, more natural wind contributes to the tunnel ventilation, and the energy saving effect is better.

Table 8. Energy-saving with the daily control strategy.

\begin{tabular}{ccc}
\hline Time Intervals & Total Power (KW) & Energy Saving (\%) \\
\hline Daytime in January & 1542 & 3.63 \\
Nighttime in January & 1764 & 0.00 \\
Daytime in February & 1542 & 3.63 \\
Nighttime in February & 1431 & 10.56 \\
Daytime in March & 1542 & 3.63 \\
Nighttime in March & 1431 & 10.56 \\
Daytime in April & 1283 & 19.81 \\
Nighttime in April & 1653 & 0.00 \\
Daytime in May & 1431 & 10.56 \\
Nighttime in May & 1542 & 3.63 \\
Daytime in June & 1431 & 10.56 \\
Nighttime in June & 1542 & 3.63 \\
Daytime in July & 1320 & 17.50 \\
Nighttime in July & 1394 & 12.88 \\
Daytime in August & 1320 & 17.50 \\
Nighttime in August & 1394 & 12.88 \\
Daytime in September & 1431 & 10.56 \\
Nighttime in September & 1542 & 3.63 \\
Daytime in October & 1283 & 19.81 \\
Nighttime in October & 1653 & 0.00 \\
Daytime in November & 1542 & 3.63 \\
Nighttime in November & 1431 & 10.56 \\
Daytime in December & 1542 & 3.63 \\
\hline
\end{tabular}

The average power of jet fans in each period and condition, and the power of fans when wind is at $2.5 \mathrm{~m} / \mathrm{s}$ are given in Table 9 for comparison. Table 9 shows that the effect of hourly control strategy is even better than the daily control strategy. If hourly control strategy were taken, it would lead to frequent change in the operational status of fans, eventually shortening the life span of jet fans.

Table 9. The energy saving benefit in different working conditions.

\begin{tabular}{cccc}
\hline \multirow{2}{*}{ Working Condition } & \multicolumn{2}{c}{ Power of Jet Fans (kW) } & \multirow{2}{*}{ Energy Saving (\%) } \\
\cline { 2 - 3 } & Left Line & Right Line & \\
\hline $2.5 \mathrm{~m} / \mathrm{s}$ & 444 & 740 & 0 \\
$1 \mathrm{~h}$ & 128.7 & 543.5 & $43.2 \%$ \\
$2 \mathrm{~h}$ & 166.8 & 633.2 & $32.4 \%$ \\
$3 \mathrm{~h}$ & 190.2 & 675.3 & $26.9 \%$ \\
$4 \mathrm{~h}$ & 223.6 & 683.2 & $23.4 \%$ \\
$5 \mathrm{~h}$ & 223.0 & 698.5 & $22.2 \%$ \\
$6 \mathrm{~h}$ & 231.7 & 710.1 & $20.5 \%$ \\
\hline
\end{tabular}

\section{Conclusions}

In this paper, an efficient ventilation method was proposed for the extra-long road tunnels in climate separation zones and a case is the ventilation issue of the Nibashan Tunnel. Due to the different climates existing at both ends of the tunnel, the natural wind has obvious effect in the tunnel ventilation. The main natural wind direction is from Lugu to Ya'an. The velocities with a guarantee rate of $95 \%$ in the sections of the main tunnel range from $2.01 \mathrm{~m} / \mathrm{s}$ to $3.14 \mathrm{~m} / \mathrm{s}$. Taking daily control strategy, the energy saving effect in July and August is the most obvious, totally $410.5 \mathrm{~kW}$ is saved, while the 
energy saving in January and December is quite little. Hourly control efficiently reduces the power of jet fans. The best energy saving percentage is $43.2 \%$. Such ventilation mode in tunnels can greatly reduce the energy consumption of the tunnel operation and provide references for the other road tunnels located in climate separation zones.

Acknowledgments: This research was supported by the Sichuan Province Science and Technology project (2015GZ0244 and 2016GFW0176), National Natural Science Foundation of China (51478393), Sichuan Provincial Education Department (SCWY16-10, 14SA0251, and 15SB0457), Chengdu Science and Technology Project (2015-HM01-00312-SF), and Sichuan Applied Psychology Research Center of Chengdu Medical College (CSXL-162213).

Author Contributions: Chun Guo conceived and wrote the paper; Chun Guo and Mingnian Wang organized the field tests; Jianfeng Xu analyzed the data and prepared the tables and figures; Lu Yang and Xiong Guo collected the data and improved the paper in grammar; and Yunlong Zhang offered useful suggestions for the preparation and writing the paper.

Conflicts of Interest: The authors declare no conflict interest.

\section{Nomenclature}

$\Delta P \quad$ natural wind resistance $(\mathrm{Pa})$;

$\Delta P_{r} \quad$ frictional pressure loss $(\mathrm{Pa})$;

$\Delta P_{\varepsilon i} \quad$ local pressure loss in the tunnel $(\mathrm{Pa})$;

$v_{i} \quad$ natural wind velocity in the tunnel $(\mathrm{m} / \mathrm{s})$;

$\xi_{\text {en }} \quad$ loss coefficient at the tunnel entrance (0.5 in the Nibashan Tunnel);

$\xi_{e x} \quad$ loss coefficient at the tunnel exit (1 in the Nibashan Tunnel);

$\lambda_{r} \quad$ loss coefficient of wall frictional resistance (0.02 in the Nibashan Tunnel);

$L \quad$ tunnel length $(\mathrm{m})$;

$D_{r} \quad$ equivalent diameter of the tunnel cross-section (m);

$\rho_{i} \quad$ air density inside the tunnel $\left(\mathrm{kg} / \mathrm{m}^{3}\right)$;

$\Delta P_{u} \quad$ ultra-static pressure difference between the tunnel portals $(\mathrm{Pa})$;

$\Delta P_{w} \quad$ dynamic pressure caused by natural wind $(\mathrm{Pa})$;

$\Delta P_{t} \quad$ thermo-potential pressure difference $(\mathrm{Pa})$;

$P_{e n}, P_{e x} \quad$ pressure at the tunnel entrance and exit $(\mathrm{Pa})$;

$P_{t} \quad$ pressure induced by vehicles $(\mathrm{Pa})$;

$P_{f} \quad$ power of fans $(\mathrm{W})$;

$P_{v} \quad$ pressure caused by ventilation equipment $(\mathrm{Pa})$;

$g \quad$ gravitational acceleration $\left(\mathrm{m} / \mathrm{s}^{2}\right)$;

$H \quad$ height difference between the tunnel portals or shafts (m);

$h_{v} \quad$ dynamic pressure $(\mathrm{Pa})$;

$\alpha \quad$ the included angle between the tunnel axes and horizontal plane $\left(^{\circ}\right)$;

$S \quad$ cross section $\left(\mathrm{m}^{2}\right)$;

$\rho_{\text {en }} \quad$ air density at the tunnel entrance $\left(\mathrm{kg} / \mathrm{m}^{3}\right)$;

$\rho_{e x} \quad$ air density at the tunnel exit $\left(\mathrm{kg} / \mathrm{m}^{3}\right)$;

$v_{\alpha} \quad$ natural wind velocity outside the tunnel $(\mathrm{m} / \mathrm{s})$ and $\alpha$ is the angle formed by wind direction

$v_{\alpha} \quad$ and tunnel axial direction $\left({ }^{\circ}\right)$;

$\rho_{\text {avg }} \quad$ average air density outside the tunnel $\left(\mathrm{kg} / \mathrm{m}^{3}\right)$;

$T_{e n} \quad$ temperature at the tunnel entrance $\left({ }^{\circ} \mathrm{C}\right)$;

$T_{e x} \quad$ temperature at the tunnel exit $\left({ }^{\circ} \mathrm{C}\right)$; specific friction resistance when wind flows in the tunnel $\left(\mathrm{kg} / \mathrm{m}^{7}\right)$ [1]. The value of $R_{m}$ is

$R_{m} \quad$ equal to the frictional resistance caused by wind of single volume. It is involved in frictional resistant coefficient $\lambda_{m}$, sectional area $S_{m}$ and sectional perimeter $P_{m} R_{m}=\frac{\lambda_{m} \rho}{8} \cdot \frac{L_{m} P_{m}}{S_{m}{ }^{3}}$;

$R_{m}^{\prime} \quad$ local wind resistance $\left(\mathrm{kg} / \mathrm{m}^{7}\right)$. It is decided by local loss coefficient $\xi_{e}$ and sectional area $S_{m}$. When the portal is entrance, $R_{m}{ }^{\prime}=\frac{\rho}{2} \cdot \frac{\zeta_{e}}{S_{m}{ }^{2}}$; when it is exit, $R_{m}{ }^{\prime}=0$;

$\rho_{\text {avg } 1}, \rho_{\text {avg } 2}$ the average air density outside the tunnel $\left(\mathrm{kg} / \mathrm{m}^{3}\right)$ and $\rho_{\text {avg } 1}=\frac{\rho_{1}+\rho_{4}}{2}, \rho_{\text {avg } 2}=\frac{\rho_{2}+\rho_{4}}{2}$. 


\section{Appendix A}

Four automatic meteorological stations were installed in the Nibashan Tunnel. The meteorological parameters collected by the stations included wind velocity, atmospheric pressure, temperature and humidity from 18 March 2008 to 16 July 2009. The probability distributions of wind velocity, temperature, atmospheric pressure around the meteorological stations are described in Figures A1-A3.

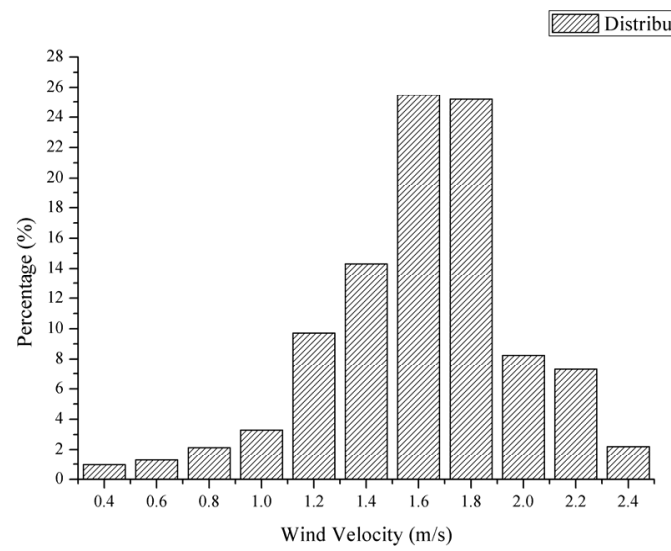

(a)

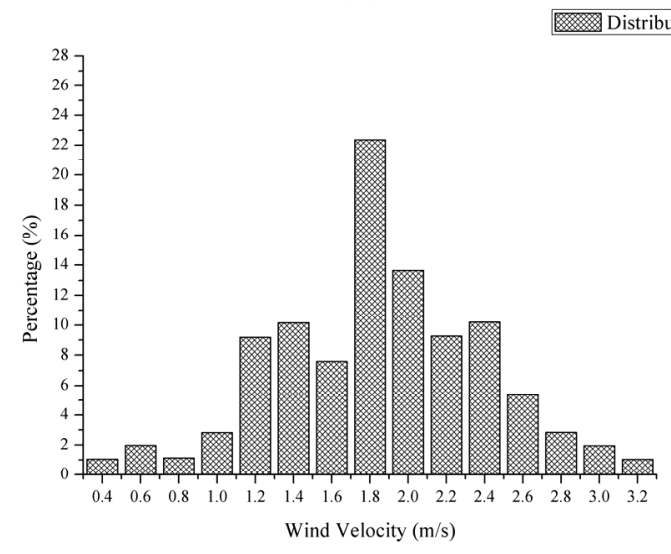

(c)

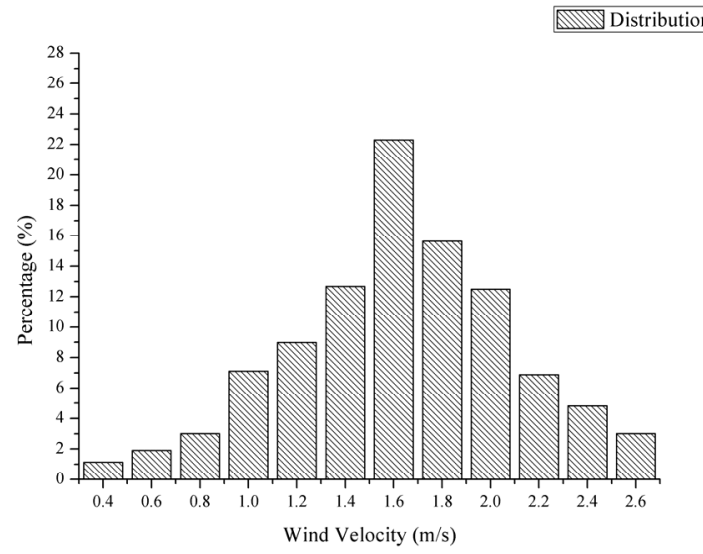

(b)

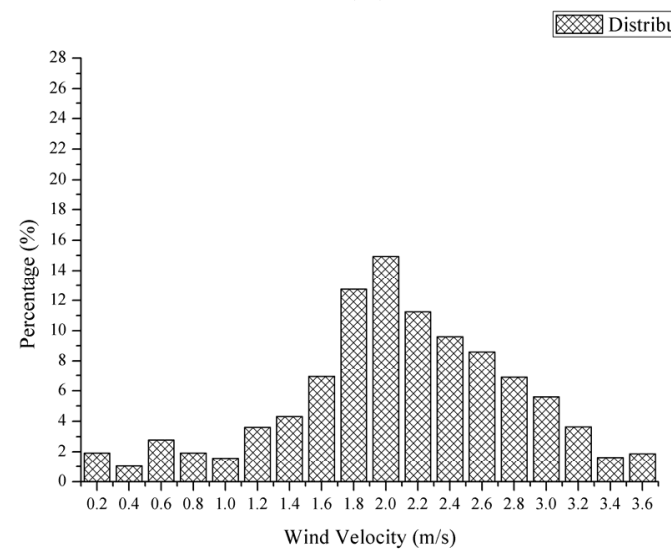

(d)

Figure A1. Wind velocity probability distribution at the meteorological stations. (a) \#1; (b) \#2; (c) \#3; (d) \#4.

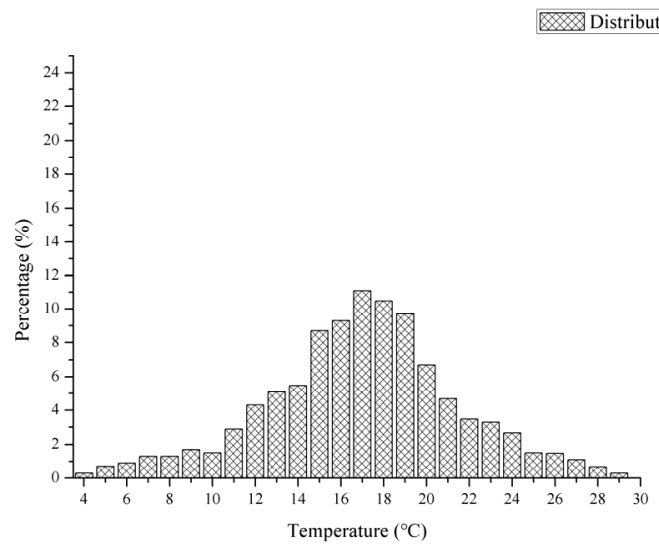

(a)

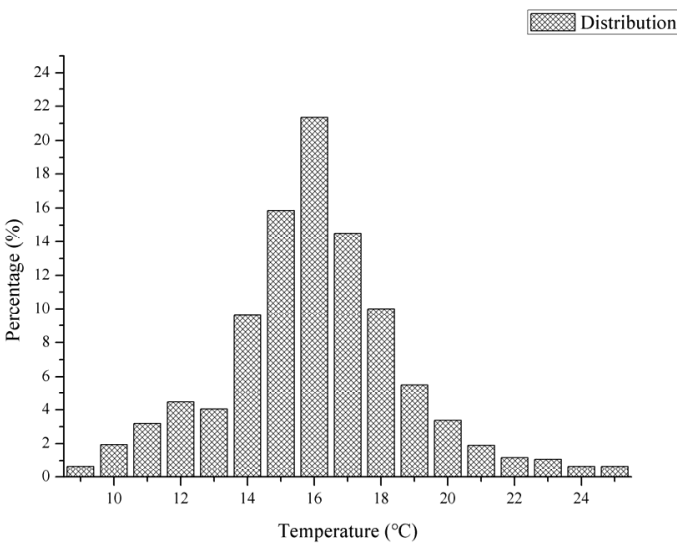

(b)

Figure A2. Cont. 


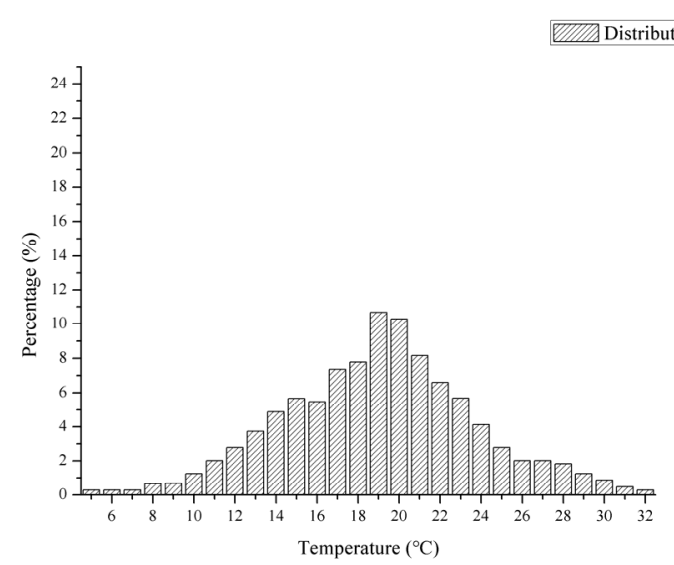

(c)

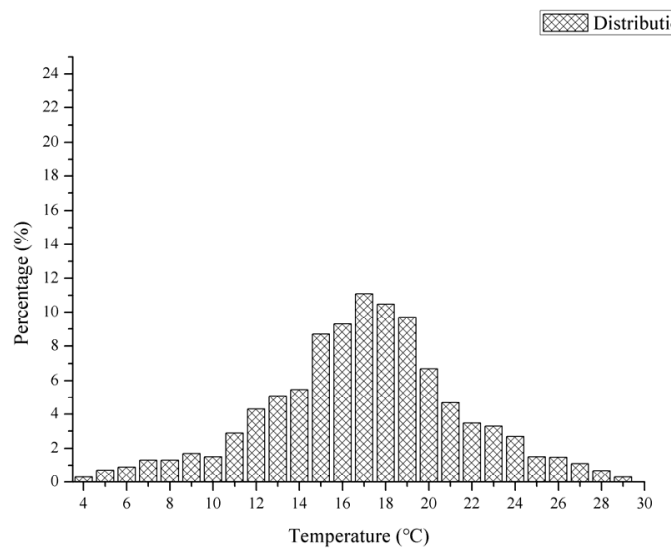

(d)

Figure A2. Temperature probability distribution at the meteorological stations. (a) \#1; (b) \#2; (c) \#3; (d) \#4.

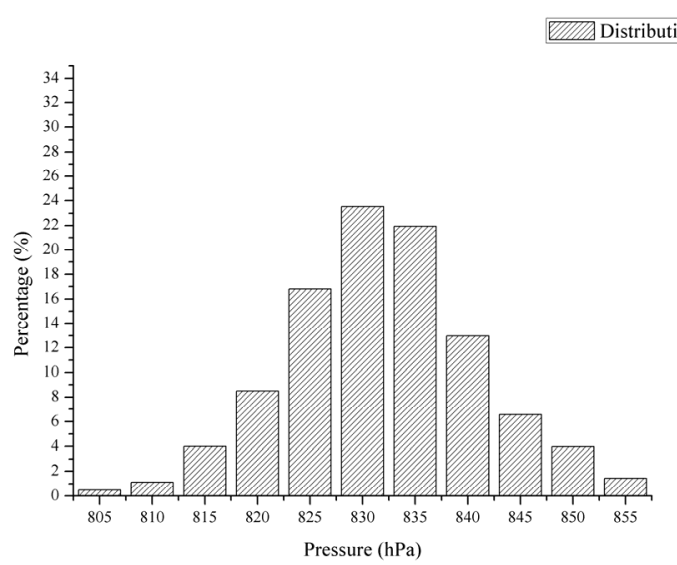

(a)

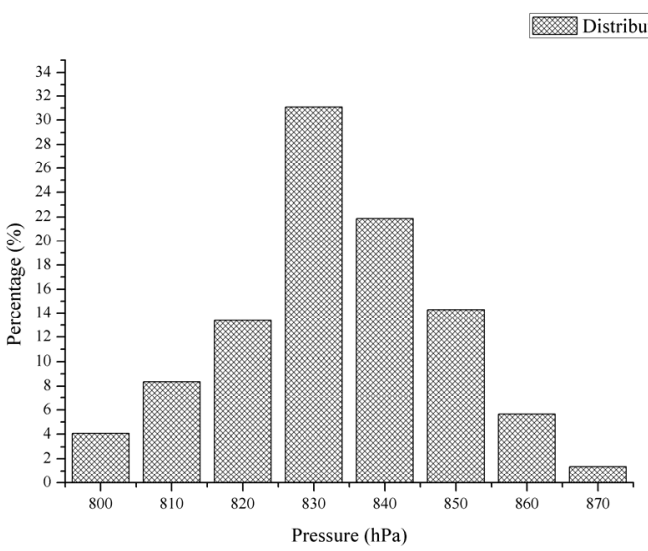

(c)

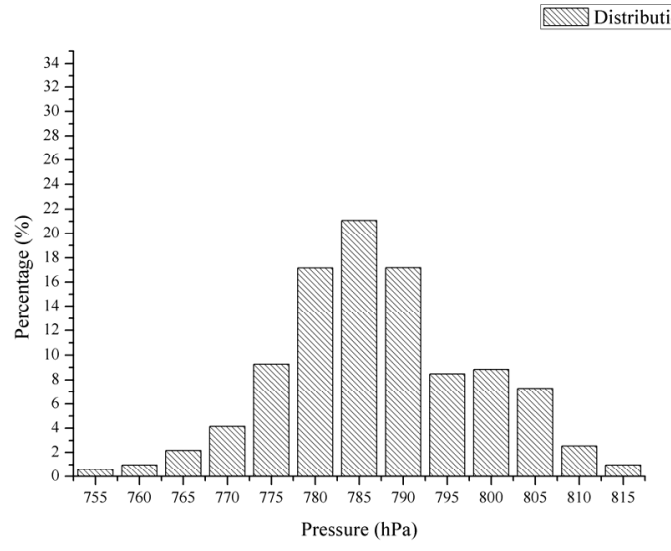

(b)

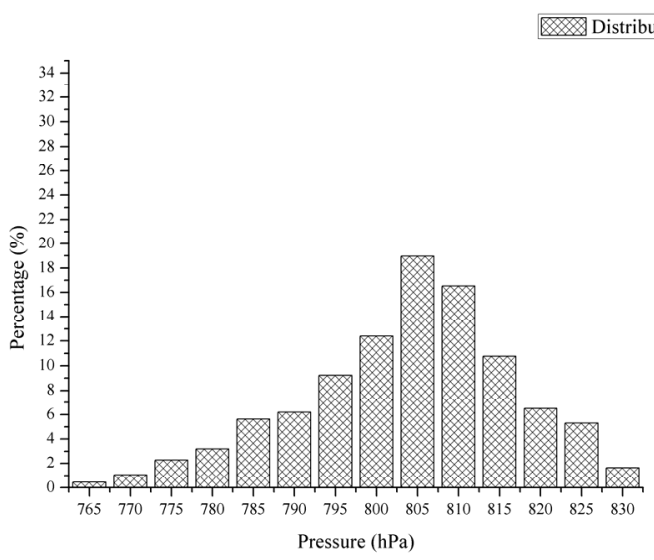

(d)

Figure A3. Atmospheric pressure probability distribution at the meteorological stations. (a)\#1; (b)\#1; (c)\#3; (d)\#4. The meteorological stations are constituted by several instruments. The parameter categories and technological indexes of the instruments are listed in Table A1. 
Table A1. Metrological properties of meteorological instrument.

\begin{tabular}{ccc}
\hline Instrument & Parameter Categories & Technological Index \\
\hline \multirow{3}{*}{ Data acquisition machine } & Environment temperature & $-40 \sim 70{ }^{\circ} \mathrm{C}$ \\
& Power supply & $220 \mathrm{~V} \mathrm{AC}$ \\
& Data storage volume & $64 \mathrm{~K}$ \\
\hline \multirow{3}{*}{ Wind sensor } & Test range of wind speed & $0 \sim 40 \mathrm{~m} / \mathrm{s}$ \\
& Test range of wind direction & $0 \sim 360^{\circ}$ \\
& Test precision of wind speed & $\pm(0.3 \pm 0.03 \mathrm{~V}) \mathrm{m} / \mathrm{s}$ \\
& Test precision of wind direction & $0.1 \%$ \\
\hline \multirow{2}{*}{ Temperature sensor } & Test range & $-50 \sim 500^{\circ} \mathrm{C}$ \\
& Resolution ratio & $0.1^{\circ} \mathrm{C}$ \\
& Test precision & $\pm 0.2{ }^{\circ} \mathrm{C}$ \\
\hline \multirow{2}{*}{ Humidity sensor } & Test range & $0 \sim 100 \% \mathrm{RH}$ \\
& Resolution ratio & $\pm 1 \% \mathrm{RH}$ \\
& Test precision & $3 \%\left(T>0{ }^{\circ} \mathrm{C}\right), \pm 5 \%\left(T \leq{ }^{\circ} \mathrm{C}\right)$ \\
\hline \multirow{2}{*}{ Air pressure sensor } & Test range & $500 \sim 1060 \mathrm{hPa}$ \\
& Resolution ratio & $0.1 \mathrm{hPa}$ \\
& Test precision & $\pm 0.5 \%$ \\
\hline
\end{tabular}

As shown in Figure 7, the main tunnel is divided into three sections. Based on the calculation method described in Section 2.1 and the data collected from the meteorological stations, the wind velocity in the sections were calculated. The wind velocity probability distributions in the sections are shown in Figure A4.

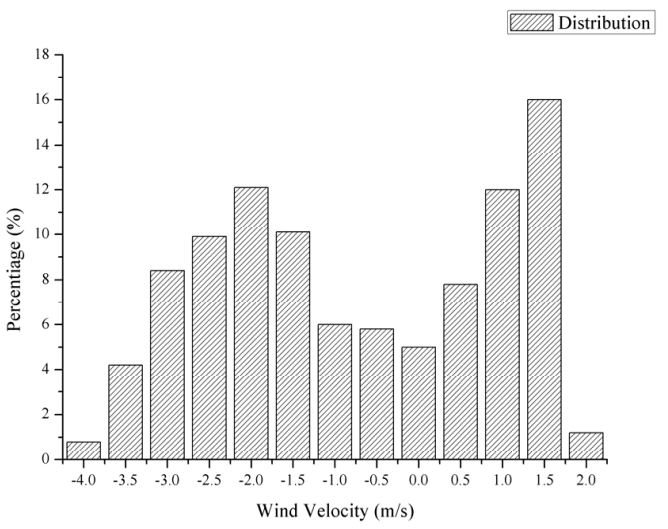

(a)

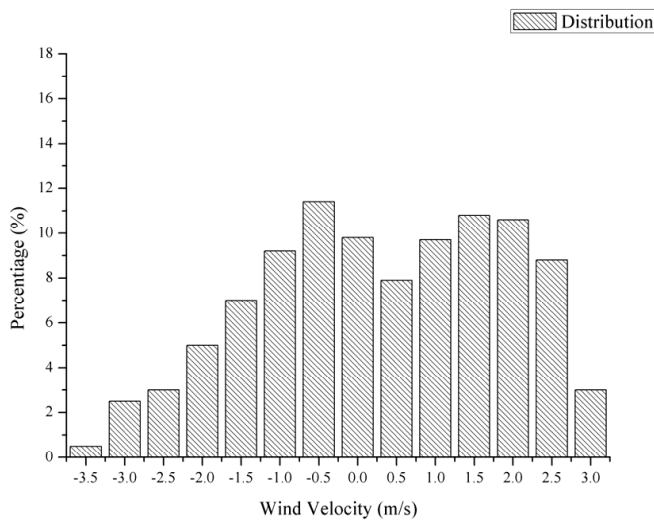

(b)

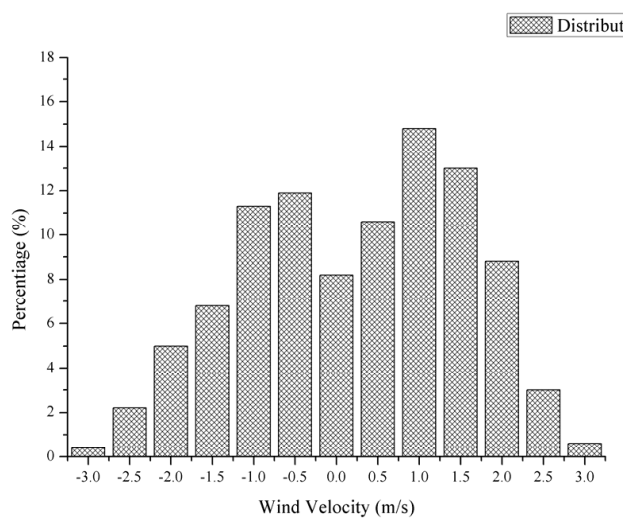

(c)

Figure A4. Wind velocity probability distribution in the Nibashan Tunnel (left line). (a) Section 1, (b) Section 2, (c) Section 3. 


\section{References}

1. Yang, L. Modern Tunneling Ventilation Technology; China Communication of the Press: Beijing, China, 2000; pp. 64-65. (In Chinese)

2. Zheng, J.; Deng, G.; Li, H. Research and analysis the meteorological factors of Queershan Tunnel. SW Highw. 2009, 4, 47-51.

3. Wang, Y. Evaluation of effect of local climate on the ventilation of the Longquan Tunnel. J. Chang'an Univ. (Nat. Sci. Ed.) 1988, 3, 59-66. (In Chinese)

4. Research Institute of Highway Ministry of Transport. Chinese Specification for Design of Ventilation and Lighting of Highway Tunnel; China Communication Press: Beijing, China, 2000; pp. 14-31.

5. Yoon, C.H.; Kim, M.S.; Jin, K. The evaluation of natural ventilation pressure in Korean long road tunnels with vertical shafts. Tunn. Undergr. Space Technol. 2006, 21, 472-477. [CrossRef]

6. Yan, T. Theoretical predictions and field measurements for potential natural ventilation in urban vehicular tunnels with roof openings. Build. Environ. 2014, 82, 450-458.

7. Tong, Y.; Liu, L.; Su, R. Experiment and numerical simulation on natural ventilation for transportation tunnel with shafts under traffic jam. In Proceedings of the 8th International Symposium on Heating, Ventilation and Air Conditioning. Lecture Notes in Electrical Engineering, Xi'an, China, 19-21 October 2013; Li, A., Zhu, Y., Li, Y., Eds.; Springer: Berlin, Germany, 2014.

8. Lin, C.; Chuah, Y.; Liu, C. A study on underground tunnel ventilation for piston effects influenced by draught relief shaft in subway system. Appl. Therm. Eng. 2008, 28, 372-379. [CrossRef]

9. Zhong, W.; Fan, C.; Ji, J.; Yang, J. Influence of longitudinal wind on natural ventilation with vertical; shaft in a road tunnel fire. Int. J. Heat Mass. Trans. 2013, 57, 671-678. [CrossRef]

10. Lesser, N.; Horowitz, F.; King, K. Transverse ventilation system of the Holland tunnel evaluated and operated in semi-transverse mode. Transp. Res. Rec. 1987, 1150, 24-28.

11. Guo, C.; Xu, J.; Wang, M.; Yan, T.; Yang, L.; Sun, Z. Study on Oxygen Supply Standard for Physical Health of Construction Personnel of High-Altitude Tunnels. Int. J. Environ. Res. Public Health 2015, 13, 64. [CrossRef] [PubMed]

12. Tang, Q.; Du, F. Efficiency Analysis of longitudinal ventilation of the Zhongliangshan Tunnel. Highway 1994, 9, 15-17. (In Chinese)

13. He, C.; Li, Z.; Fang, Y.; Wang, M. Feed-forward intelligent fuzzy logic control of highway tunnel ventilation system. J. Southwest Jiaotong Univ. 2005, 5, 575-579. (In Chinese)

14. Zhang, G.; Lei, B. Neural network online control to road tunnel with longitudinal ventilation. J. Southwest Jiaotong Univ. 2005, 6, 765-767. (In Chinese)

15. Karakas, E. The control of highway tunnel ventilation using fuzzy logic. Eng. Appl. Artif. Intell. 2003, 16, 717-721. [CrossRef]

16. Nagataki, K.; Kotsuji, C.; Yahiro, M.; Funabashi, M.; Inoue, H. Scheme and operation results of highway tunnel ventilation control using hybrid expert system technology. Hitachi Rev. 1992, 41, 51-58.

17. Tan, Z.; Huang, Z.; Wu, K.; Xu, L. Simulation analysis of longitudinal ventilation system with jet fan velocity control for MPC strategy in a road tunnel. In Proceedings of the 15th International IEEE Conference on Intelligent Transportation Systems, Anchorage, AK, USA, 16-19 September 2012; pp. 1471-1476.

18. Du, P.; Luo, $X$. The research of urban road tunnel longitudinal ventilation control based on RBF neural network. In Proceedings of the 2nd IITA International Conference on Geoscience and Remote Sensing (IITA-GRS), Qingdao, China, 28-31 August 2010; pp. 85-87.

19. Tang, Z.; Wang, M.; Yu, L.; Chao, F. Study on the Energy-saving Technology for Frequency Varied Ventilation in the Hong Kong-Zhuhai-Macao Bridge's Tunnel Project. Chin. J. Undergr. Space Eng. 2012, 8, 1418-1421.

20. Chu, B.; Hong, D.; Park, J. Tunnel ventilation control via an actor-critic algorithm employing nonparametric policy gradients. J. Mech. Sci. Technol. 2009, 1, 311-323. [CrossRef]

21. Chen, P.; Lai, J.; Lin, C. Application of fuzzy control to a road tunnel ventilation system. Fuzzy Sets Syst. 1998, 1-3, 9-28. [CrossRef]

22. Funabashi, M.; Aoki, I.; Yahiro, M.; Inoue, H. A fuzzy model based control scheme and its application to a road tunnel ventilation system. In Proceedings of the International Conference on Industrial Electronics, Control and Instrumentation, Kobe, Japan, 28 October-1 November 1991; IEEE: Boston, MA, USA, 1991; pp. 1596-1601. [CrossRef] 
23. Bogdan, S.; Birgmajer, B.; Kovacic, Z. Model predictive and fuzzy control of a road tunnel ventilation system. Transp. Res. C Emerg. Technol. 2008, 5, 574-592. [CrossRef]

24. Lan, H.; Luo, W.; Kong, F. Research on fuzzy control for highway tunnel longitudinal ventilation system. J. Syst. Simul. 2006, 12, 3520-3523.

25. Yang, C.; Wang, Z. Current status and development trend of ventilation technology for highway tunnel. Chin. J. Undergr. Space Eng. 2011, 7, 819-824. (In Chinese)

26. Paolo, P. Natural Ventilation and Induced Ventilation of Traffic in Road Tunnel. Ingegneria Ferroviaria 1980, 35, 459-469.

27. Ji, L.; Tan, H.; Kato, S.; Bu, Z.; Takahashi, T. Wind tunnel investigation on influence of fluctuating wind direction on cross natural ventilation. Build. Environ. 2011, 46, 2490-2499. [CrossRef]

28. Bring, A.; Malmstrom, T.G.; Boman, C.A. Simulation and measurement of road tunnel ventilation. Tunn. Undergr. Space Technol. 1997, 12, 417-424. [CrossRef]

29. Ministry of Communications of the People's Republic of China. Guidelines for Design of Ventilation of Highway Tunnels, 1st ed.; China Communication Press: Beijing, China, 2014; pp. 37-39.

30. Guo, C.; Wang, M.; Yang, L.; Sun, Z.; Zhang, Y.; Xu, J. A review of energy consumption and saving in extra-long tunnel operation ventilation in China. Renew. Sustain. Energy Rev. 2016, 53, 1558-1569. [CrossRef]

31. Li, Y.; Liu, J.; Ju, J. Analysis method of natural wind pressure based on thermodynamics. Expr. Inform. Min. Ind. 2007, 456, 26-28. (In Chinese)

32. Mao, J.; Huang, Y.; Zhou, J.; Xing, Z. Energy-saving and economic study of natural ventilation in city tunnel. Appl. Mech. Mater. 2012, 178-181, 92-97. [CrossRef]

33. Zheng, X.; Guo, J. Research on non-mechanical ventilation effect in Zhongnanshan Road Tunnel. Eng. Sci. 2010, 3, 39-45.

34. Liu, C.; Guo, J. Field test and analysis of ventilation effect of the Zhongnanshan Highway Tunnel. Tunn. Constr. 2009, 1, 28-32.

35. Bao, Z.; Zhu, L. Research on the energy-saving strategy of electromechanical system of highway tunnel. West. China Commun. Sci. Technol. 2012, 8, 227-229. (In Chinese)

36. Sun, S.; Li, G.; Yu, N.; Yang, G.; Xie, J. Feasibility Analysis of Natural Ventilation of an Internal-Combustion Tract Single-Line Tunnel between 2-4 km in the Plateau Region. Mod. Tunn. Technol. 2011, 5, 107-114. (In Chinese)

37. Zhang, G. Optimization Design of Operation and Ventilation System of Fenshuiling Extra-long Tunnel. Transp. Stand. 2014, 16, 173-178. (In Chinese)

38. Wang, G.; Li, Z.; Zhou, R. Study of the natural ventilation of the Yuanliangshan tunnel after construction. Tunn. Constr. 2004, 24, 28-30. (In Chinese)

(C) 2017 by the authors. Licensee MDPI, Basel, Switzerland. This article is an open access article distributed under the terms and conditions of the Creative Commons Attribution (CC BY) license (http:/ / creativecommons.org/licenses/by/4.0/). 